\section{SUNY ONEONTA}

Lyndsey E. Farrar and Leigh M. Fall

Dept. of Earth \& Atmospheric Sciences, SUNY Oneonta, Oneonta, NY 13820

\section{SUNY} ONEONTA $\frac{\text { Introduction }}{\text { Body size of org }}$

is is a sificant characteristic associated with metabolic rate, extinction, and other ecological and evolutionary traits. Body size has also been linked to species abundance;
the number of individuals supported by an environment is limited due to resource allocation. The Middle Ordovician Trenton Group located in central New York represents deposition of shallowshelf carbonates to deep-water shales within the Taconic foreland basin. Cisne and Rabe (1978) gradient. Other environmental factors change in conjunction with water depth and influence the distribution of fauna that live along the sea floor. The trilobite Flexicalymene is found throughout the Trenton Group but is restricted to shallower water relative to Triarthrus, a deep-water genus (Cisne et al., 1980; 1982). It is unknown whether there is a difference in body size between the two genera along the gradient. The findings of this study will provide information on triliobite
distribution to help elucidate environmental factors within the Taconic foreland basin.

Hypothesis \& Prediction

Hypothesis: There is a greater abundance of the smaller-bodied trilobite species on the deeper part of the Taconic Basin.

Prediction: A greater abundance of smaller Triarthrus fossils will dominate the deeper portion of the
Taconic basin, while the larger Flexicalymene fossils will be more abundant in shallow areas of the Taconic
basin.

\section{Geologic Background}
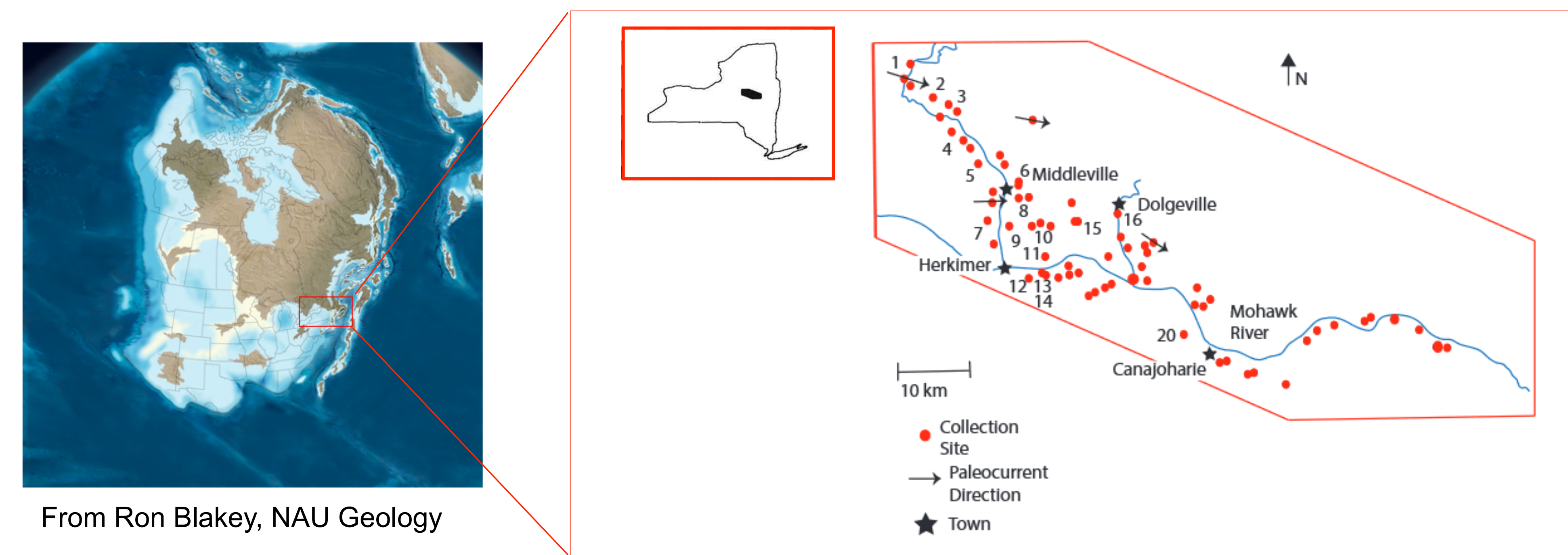

The study area is the Taconic foreland basin that formed as a result of the collision between the eastern coast of North America and a volcanic island art system. The Midales,
Trenton Group was deposited within the basin. It contains limestones and shales,

representing shallow-water deposition in the west and deep-water deposition in the east. The map on the right shows the locations of John Cisne's fossil collections. Paleocurrent information is based on fossils, mainly graptolites. Modified from Cisne et al. (1982). (A)
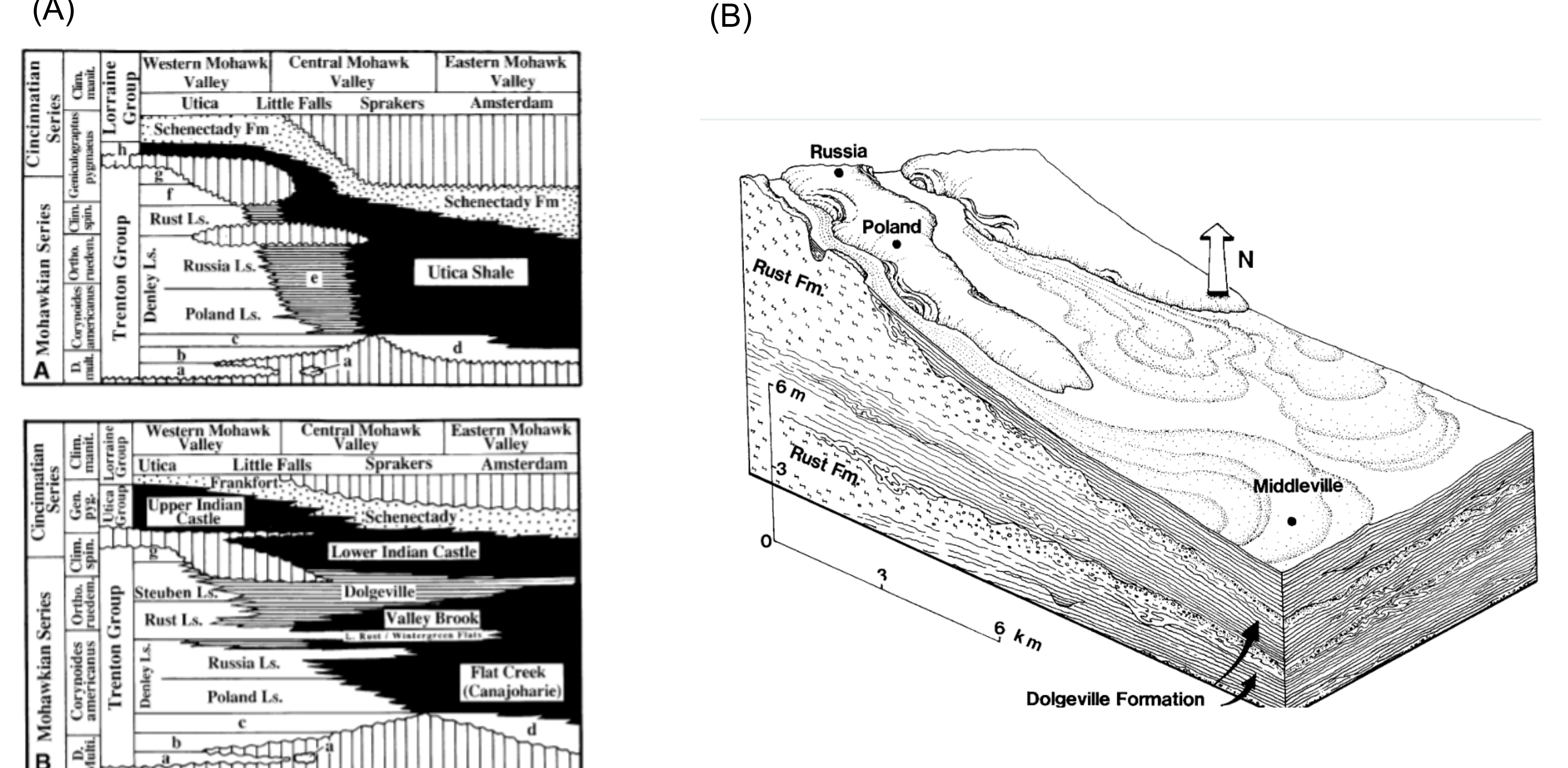

Stratigraphy of the Trenton Group. (A) The top chronostratigraphic chart comes from Fisher (1977) and Hay and Cisne (1988). Brett and Baird (2002) revised the stratigraphy, which is shown in the lower panel. (a) Napanee Formation (b) Kings Falls Limestone (c) Sugar River
Formation (d) "Glens Falls Formation" or undifferentiated lower Trenton Group (e) Dolgeville facies (f) Steuben Limestone (g) Hillier Formation (h) Deer River Shale. From Brett and (2002). The trilobite Triarthrus was coll he Doly (hily fom the Dolgoville Fomation.
Material and Methods

John Cisne's Trenton Group collections are currently housed at the Paleontological Research Institution in Ithaca, NY. Over the
summer, collections had to be organized before we could begin summer, collections
our study (Fig. 1).

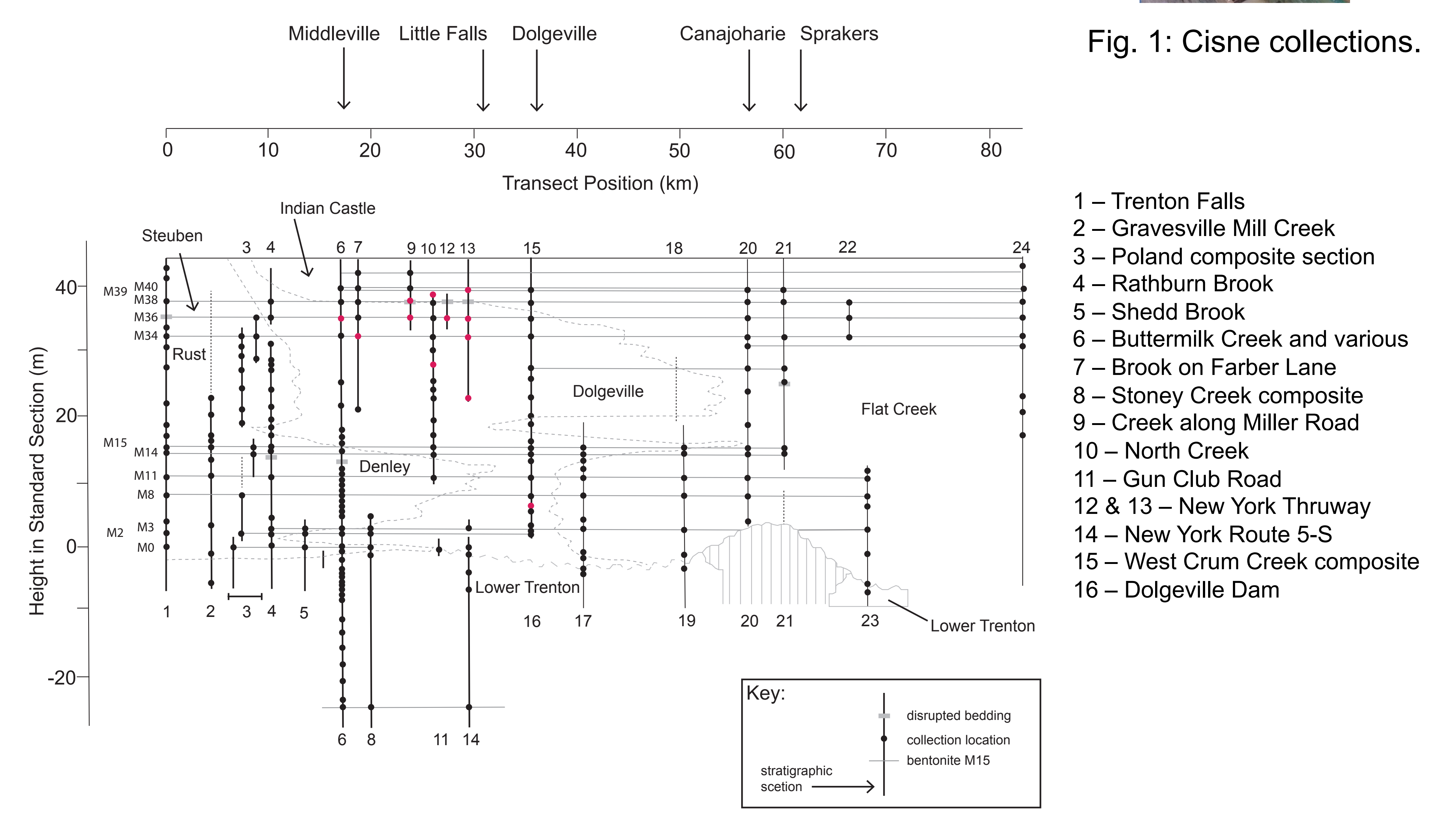

Cross section of the Trenton Group modified from Cisne et al. (1982) showing the distribution of collections. Each vertical line represents a stratigraphic column at a single location. The black dots represent a collection and red dots represent the collections used in this study. Cisne made collections in relation to the bentonites. At most sampling bentonite beds. Bentonite M15 represents the point at which there was a transgression bentonite beds. Bentonite M15 represents the point at which there was a transgression
the basin and shoreline moves westward (Cisne and Rabe, 1978). The cross section corresponds to the study area map. Sections $1-16$ were used in this study.

(A)
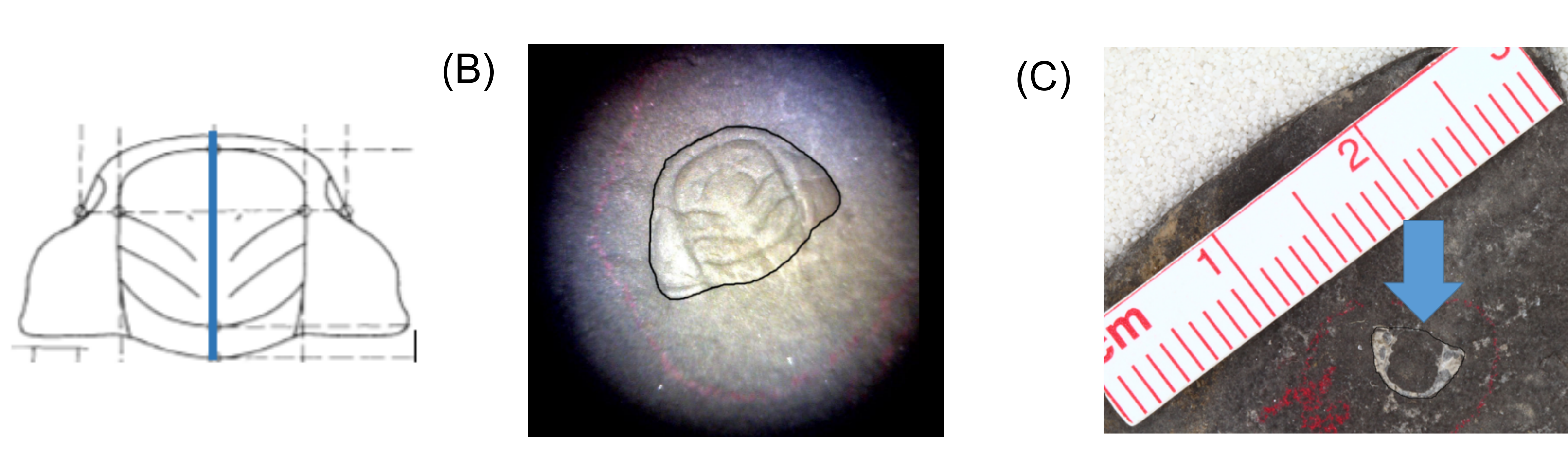

Cephalon length measurements. Due to preservation of Triarthrus, cephalon length was used as a proxy for body size (Trammer and Kaim, 1997). The cephalon was photographed and measured using ImageJ. (A) Blue line shows cephalon length
measurement. Modified from Cisne et al. (1980). (B) Cephalon from collection 144-2. measurement. Modified from Cisne et al. (1980). (B) Cephalon from collection 144-2.
Photographed under 0.7 X 10 magnification. (C) Cephalon from collection 84-1.

Detrended correspondence analyses (DCA) and bar plot were run with abundances obtained from Cisne's notes. To test for differences in body size, Kruskal-Wallis and Mann-Whitney (Wilcoxon) tests were performed. All analyses run in R.

References
Brett, C.E., and Baird, G.C., 2002, Revised stratigraphy of the Trenton Group in its type area, central New York State: sedimentology and tectonics of a Middle Ordovician shelf-to-basin succession: Physics and Chemistry of the Earth, Parts AB/C, v. 27, p. 231-263. Cisne, J.L., Molenock, J., and Rabe, B.D., 1980, Evolution in a cline: the trilobite Triarthrus along an Ordoviciain depth gradient: Lethaia, v.13, p.47-59.
Cisne, J.L., possible parapatric speciation: the trilobite Flexicalymene senaria along an Ordovician depth gradient: Trammer, J, and Kaim, A., 1997, Body size and diversity exemplified by three trilobite clades: Acta
Palaeontologica Poloncia, v. 42, p. 1-12.
Results

Cinse and Rabe (1978) identified a water depth gradient based on fossil collections. Results from - Body size within also show a separation of taxa and collections along axis 1 and 2 (Fig. 2). section (Fig. 3A). Median cephalon length: $4.63 \mathrm{~mm}$ (M34) and $5.15 \mathrm{~mm}$ (M36) - Body size within sections 6, 9, and 13 do show a significant change (Kruskal-Wallis $\chi^{2}=6,3537$, $\mathrm{p}=0.04172$ ) but this result may be due to the small sample size in section 6 (Fig. $3 \mathrm{~B}$ ). There is no significant body size change (Mann-Whitney W=95, $\mathrm{p}=0.06134)$ between sections 9 and 13 .
Median cephalon length: $5.40 \mathrm{~mm}$ (section 6), $3.62 \mathrm{~mm}$ (section 9), and 5.15 (section 13). Flexicalymene is more abundant in the shallow water sections (Denley Ls., Rust Ls, and Steuben

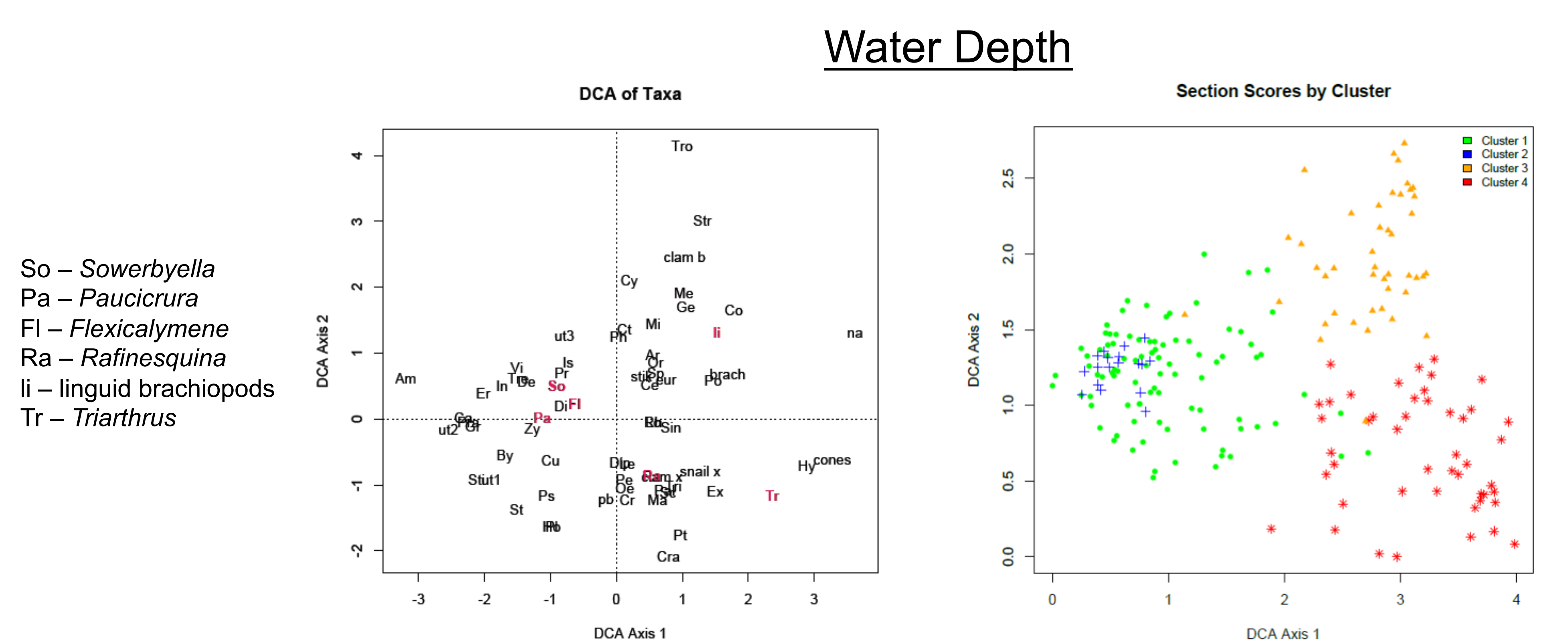

Fig. 2: DCA ordination of t taxa (leff) and samples (right). The taxa that are highlighted in red
represent the taxa with the greatest abundances. Glusters $1-4$ identified in the ordination by samples was determined by a R-mode cluster analysis.

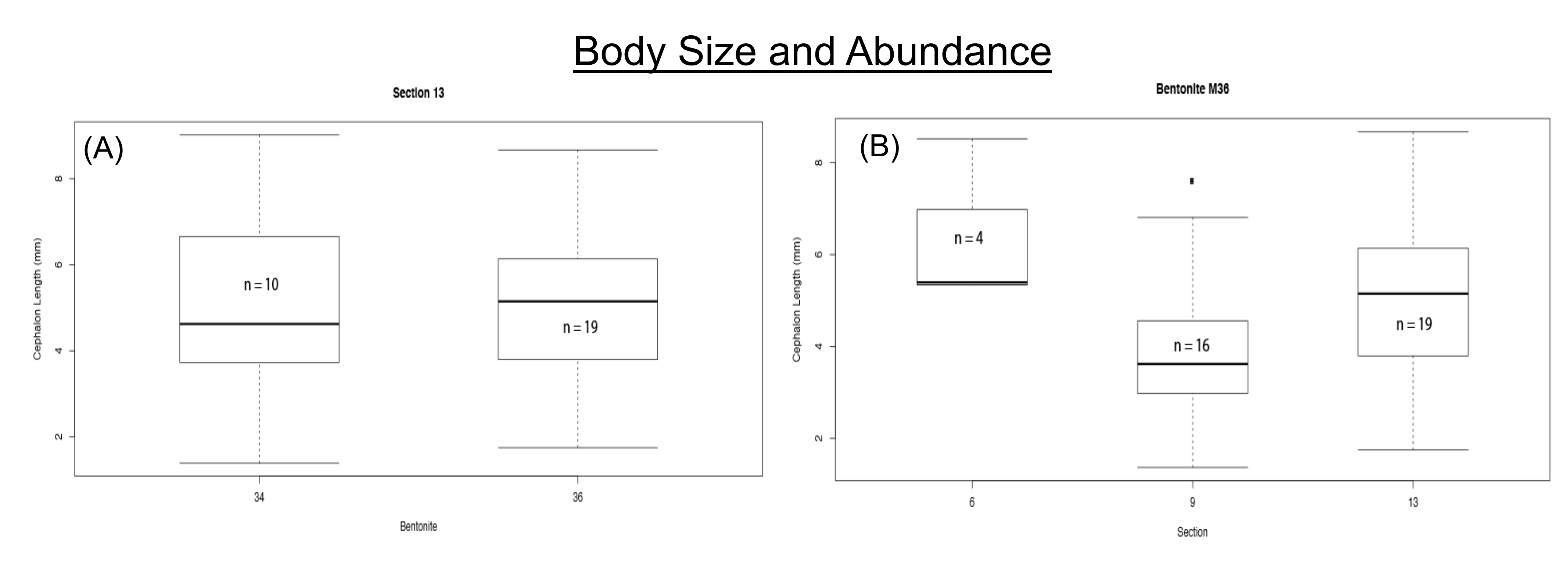

Fig. 3: Plots showing distribution of Triarthrus cephalon lengths. (A) Body size of Triarthrus through
time. (B) Body size of Triarthrus across the basin.

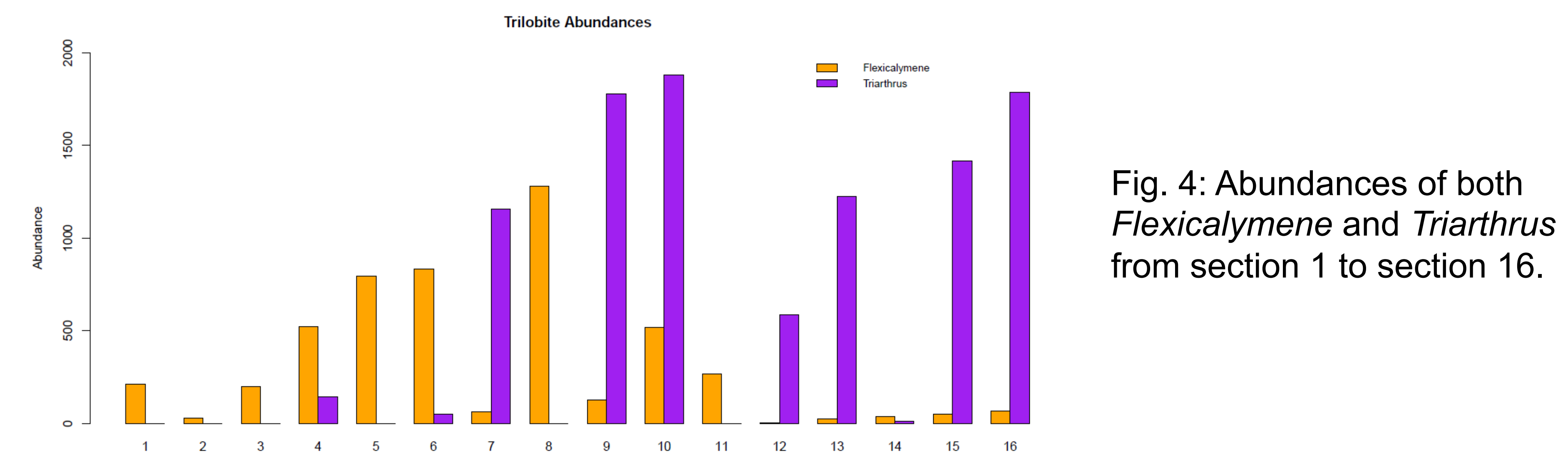

Next Steps

Obtain Flexicalymene fossils to measure and compare body size with Triarthrus along the depth gradient.

samples.

\section{Acknowledgments}

Lells Grantd line to thank the Paleontological Research Institution for receiving the John W. Wells Grants-in Aid of Research, the Paleontological Society for receiving the Allison R. "Pete" Creative Activity grant. 